\title{
PRAGMÁTICA E COGNIÇÃO OU O PROCESSO INFERENCIAL DE BRASILEIROS NA APRENDIZAGEM DA LÍNGUA ESPANHOLA
}

\begin{abstract}
PRAGMATICS AND COGNITION OR THE INFERENTIAL PROCESS OF BRASILIANS IN LEARNING SPANISH LANGUAGE
\end{abstract}

\author{
Sebastião Lourenço dos Santos ${ }^{1}$ \\ Universidade Estadual de Ponta Grossa (UEPG)
}

Resumo: Nossa comunicação é essencial para que possamos interagir nas atividades que efetuamos em sociedade, sendo a recorrência à linguagem verbalizada uma forma bastante produtiva para a execução da prática comunicativa. Tendo em vista esses pressupostos e utilizando como aporte teórico a Teoria da Relevância (SPERBER; WILSON, 2001), analisamos treze produções textuais de língua espanhola, na Universidade Estadual de Ponta Grossa, com o objetivo de descrever como ocorrem os processos inferenciais dos alunos brasileiros na aprendizagem do artigo neutro " 10 ". Acreditamos que este breve estudo pode lançar alguma luz sobre a descrição da competência comunicativa de aprendizes brasileiros de língua espanhola. Palavras-Chave: Cognição; Inferência; Relevância.

\footnotetext{
1 Endereço eletrônico: lorecutp@hotmail.com
} 


\begin{abstract}
Our communication is essential for us to interact in activities that we perform in society, whereas recurring to verbal language is a very effective way of communicating. The learning process of Spanish language is one of them. Given these assumptions and using as theoretical Support the Theory of Relevance (SPERBER; WILSON, 2001), we analyze thirteen textual productions of Spanish language, in the State University of Ponta Grossa, Paraná, Brazil, whit the objective of describing how the inferential processes of Brazilian students occur in learning the neutral article "lo". We believe that this brief study can shed some light on the description of communicative competence of Spanish-speaking Brazilian learners.
\end{abstract}

Keywords: Cognition; Inference; Relevance.

\title{
INTRODUÇÃO
}

A evolução da linguagem humana proporcionou não só a manutenção do homem em sociedade, mas, e principalmente, determinou sua sobrevivência no mundo até os dias de hoje, afinal, é por meio da linguagem verbal que as pessoas interagem racionalmente umas com as outras intercambiando informações diversas (MERCIER; SPERBER, 2017). Entre as principais atividades linguísticosociais que o homem experimenta como ser social, a que se evidencia substancialmente é a que ele vivencia no ambiente escolar.

No processo de formação escolar, as discussões que tratam dos métodos e técnicas sobre o ensino-aprendizagem de línguas estrangeiras se destacaram no final do século 20 e continuam gerando calorosos debates nestas duas últimas décadas, o que prova que o assunto não se esgota, pois há uma preocupação constante em torno de como devem ser as ações metodológicas em sala de aula. Pensando nisso, estudiosos como Canale (1995), Pérez (1999), Abadia (2000), entre outros, propuseram várias hipóteses, métodos e enfoques de como tornar mais produtivo o processo de ensino-aprendizagem de língua estrangeira.

Para ilustrar um pouco o tema, tomando o viés da pragmática cognitiva da Teoria da Relevância (SPERBER; WILSON, 2001), neste estudo esboçamos um breve panorama do processo inferencial de brasileiros aprendizes de Espanhol como Língua Estrangeira (E/LE). O objetivo do estudo é descrever, ainda que 
sucintamente, como ocorre o processo inferencial de aprendizagem do aluno brasileiro sobre o artigo masculino singular "el" e do artigo neutro "lo" em textos escritos de Língua Espanhola. No caso da produção textual de alunos brasileiros aprendizes de E/LE, a questão que se levanta é: cognitivamente, que regra ou quais regras inferenciais atuam no processo de aprendizagem do aluno?

A hipótese a ser testada, distintamente dos estudos contrastivos que se orientam, na maioria das vezes, por aspectos morfossintáticos, é a de que o aluno brasileiro usa o artigo neutro "lo" no lugar do artigo "el" porque cognitivamente ao recorrer ao conhecimento enciclopédico da Língua Materna (LM), por falsa analogia (ou falsa seleção), perfaz inferências cujas premissas são gramaticalmente ${ }^{2}$ equivocadas na língua espanhola. Este estudo, porém, não se presta a elaboração de uma análise contrastiva na aprendizagem de espanhol por estudantes brasileiros, no molde que fizeram (ou fazem) muitos pesquisadores como Durão (2004), Andrade (2011), Carvalho (2013), Moysés (2014), Silva (2015), Eckert (2017) e outros.

O corpus tem como objeto de análise treze textos produzidos por alunos do $2^{\underline{o}}$ ano do Curso de Licenciatura em Letras Português-Espanhol da Universidade Estadual de Ponta Grossa, turno vespertino, no ano de 2018.

\section{A TEORIA DA RELEVÂNCIA}

Nas últimas cinco décadas, no mundo todo, as quatro principais teorias pragmáticas (Atos de Fala, de Austin (1962) e Searle (1969), Teoria das Implicaturas Conversacionais, de Grice (1975), Teoria da Relevância, de Sperber e Wilson (1986/2001) e Teoria da Polidez, de Brown e Levinson (1987)) impulsionaram substancialmente os estudos da linguagem e possibilitaram

2 Neste ponto, por "gramática" tomamos como referência o conceito de "gramática internalizada", de Possenti (1996), conceito que se coaduna com as ideias de Sperber e Wilson $(1986 / 2001)$. 
vários insights sobre aspectos linguísticos obscuros à Psicologia Cognitiva. Neste estudo não faremos uso das duas primeiras nem a última, posto que o objeto de estudo requisita os pressupostos da Teoria da Relevância.

O modelo pragmático proposto por Sperber e Wilson (1986/2001), conhecido como Teoria da Relevância (TR), tem a racionalidade humana como construto operacional do comportamento comunicativo. Segundo os autores, na comunicação a racionalidade tende naturalmente a selecionar os estímulos que são potencialmente mais relevantes e a processá-los de maneira mais produtiva. Nesse modelo, a cognição humana se orienta por uma busca natural de alto efeito contextual (benefício) com um mínimo de esforço (custo) de processamento das informações. Nessa perspectiva, a relevância pode ser comparada a níveis de produtividade, como uma relação de custo-benefício. Essa relação do efeito/esforço que orienta o conceito de relevância prediz que quanto maior o benefício e menor o custo de processamento, maior é a relevância de um ato comunicativo.

Conforme Sperber e Wilson (1986/2001), a comunicação entre pares é possível porque a cognição humana tende a dirigir-se à relevância ótima, conceito que Grice deixou vago em seus postulados conversacionais de 1975. Para a TR, a relevância é uma propriedade psicológica que faz com que uma informação valha a pena ser processada em termos de esforço e efeito cognitivo de processamento, porque, dadas as especificidades contextuais, a interpretação modifica e reorganiza suposições factuais (pensamentos) na mente das pessoas.

No modelo pragmático relevantista³, o cálculo inferencial humano processa informações novas com informações conhecidas já armazenadas na Memória Enciclopédica - conjunto de conhecimentos inerentes aos indivíduos contendo as experiências, vivências e saberes adquiridos ao longo de sua vida -

\footnotetext{
${ }^{3}$ Linha pragmática que tem como suporte teórico a Teoria da Relevância, de Sperber e Wilson (1986/2001).
} 
e deriva conclusões válidas. Por esse viés, o processamento dedutivointerpretativo humano, sendo ostensivo-inferencial, cessa quando o efeito de interpretação informativa atinge a relevância ótima, isto é, quando o efeito de interpretação for grande.

Nessa perspectiva, o trabalho dedutivo de interpretação humana é comandado pelo "Princípio Cognitivo de Relevância", princípio segundo o qual a atenção do interagente ${ }^{4}$ e seus recursos cognitivos de processamento estão dirigidos para a maximização daquelas informações que lhe são (mais) relevantes em um dado contexto. A figura 1 ilustra esse procedimento inferencial de interpretação humana.

Otimização da Relevância Informativa

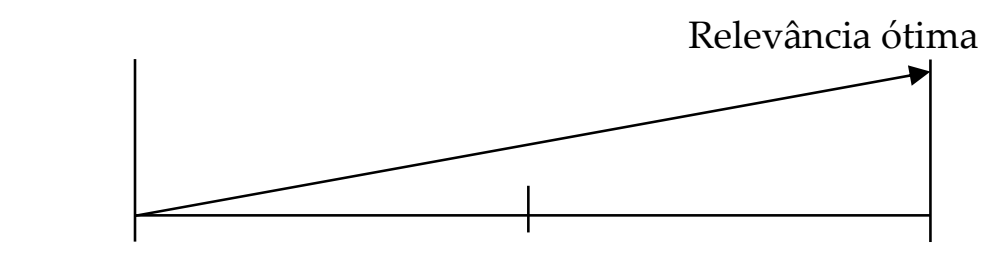
Efeito pequeno
Efeito médio
Efeito grande

Figura 1 - criação do autor

Assim sendo, com base nos pressupostos teóricos da TR, a ideia que subsidia este estudo é a de que, na produção escrita, as informações mais relevantes ao aluno brasileiro aprendiz de E/LE são aquelas que exigem menor esforço de processamento e causam maior efeito de aprendizagem. Essa premissa conduz a uma segunda ideia: a de que na produção textual a intenção do aluno é otimamente relevante se, e apenas se, o significado apreendido é

\footnotetext{
${ }^{4}$ Para fins didáticos, neste artigo adotamos o termo "interactuante" para referirmos ao produtor de uma elocução (sentença, enunciado ou fala). No mesmo sentido, adotamos o termo "interagente" para a pessoa que interage (reage) com o interactuante. Quando nos referimos a ambos simultaneamente, adotamos o termo "interagentes".
} 
suficientemente relevante para valer a pena ser processado, porque é o mais compatível com as expectativas e preferências do aluno/interactuante.

De acordo com a TR, a manifestação social de um enunciado, seja ele oral ou escrito, é uma espécie de núcleo comum do significado que é partilhado por todas as elocuções que se baseiam nessa conexão. No entanto, as elocuções orais ou escritas não servem somente para externar pensamentos humanos, mas revelam, entre outras coisas, atitudes sobre estados mentais (anseios, desejos, frustrações, alegrias, ambições, etc.) dos indivíduos e sua relação com o pensamento expresso em tais elocuções. A pressuposição que se encontra por trás dessa ideia é que os interagentes estabelecem certos padrões de veracidade e de valor informativo às elocuções de modo que só comunicam informações que se coadunam a esses padrões.

Para a Pragmática, na comunicação humana o contexto desempenha um fator crucial, uma vez que ele afeta diretamente tanto a produção quanto a interpretação de enunciados, fazendo com que cada elocução tenha diferentes significados em cada situação comunicativa. A TR concebe o contexto como um construto mental formado por um subconjunto de pensamentos que os interagentes têm do mundo, suposições estas que afetam a interpretação das elocuções porque acrescentam algum conhecimento ao conjunto de contextos potenciais dos indivíduos. Santos (2013) descreve o contexto como sendo,

[...] o ambiente abstrato, dinâmico, vivo, comum, mas não idêntico, a dois ou mais participantes de um intercâmbio conversacional, que de acordo com as contingências circunstanciais, orienta, restringe ou amplia a tomada de decisões dos interlocutores, enriquecendo ou saturando a linguagem humana com informações linguísticas e não linguísticas relevantes à produção e à interpretação de significados comunicados e inferidos conversacionalmente. (SANTOS, 2013, p. 707-708). 
Para Sperber e Wilson (1986/2001), o contexto não está restrito somente ao ambiente físico do mundo real ou ao co-texto ${ }^{5}$ (BAR-HILLEL, 1982), mas deve alinhar-se às expectativas que se tornam acessíveis no processamento das informações, tais como hipóteses científicas, crenças e valores culturais, e saberes dos interagentes. Ou seja, para a TR o contexto é um construto psicológico de suposições que o indivíduo tem do mundo. Nesse sentido, o contexto é sempre um construto mental no qual as representações do mundo são aceitas como verdadeiras, ou como provavelmente verdadeiras, e ao qual os indivíduos recorrem no instante do processamento de uma nova informação.

Existe, por certo, na comunicação verbalizada uma codificação e uma decodificação linguística, mas o significado que o interactuante pretende intencionalmente comunicar fica aquém do código linguístico - este é apenas uma parcela da evidência sobre as intenções do interactuante e auxilia o interagente a inferir o que o interactuante tenciona informar. A concepção base que norteia a TR é a de que em um conjunto de suposições (pensamentos), aquilo que é comunicado por uma elocução (declarativa, por exemplo) é o significado explicitamente expresso por uma suposição. As outras, se houver, são comunicadas implicitamente, ou implicadas. Em um enunciado, o que diferencia o seu conteúdo explícito da implicatura é: enquanto o conteúdo explícito pode ser decodificado linguisticamente a implicatura só pode ser inferida ostensivamente.

Logo, como somos seres cognitivamente idiossincráticos, de acordo com nossas experiências e estados psicológicos que estão ligados às nossas representações, temos e fazemos representações diferentes do mesmo mundo. De acordo com Sperber e Wilson, nossas representações podem ser parecidas

\footnotetext{
${ }^{5}$ Segundo Bar-Hillel o co-texto é o conjunto de unidades verbais que fixam o significado das outras formas linguísticas, isto é, o conjunto de objetos contextuais necessários para o processamento e interpretação do significado.
} 
quando se referem a coisas físicas e ao ambiente, mas nunca iguais em relação à nossa capacidade cognitiva. Sperber e Wilson (1986/2001) explicam que,

Todos os seres humanos estão, na verdade, constrangidos pelas capacidades cognitivas que são especificamente da sua espécie no que se refere ao desenvolvimento de suas representações de mundo, e é também verdade que todos os membros do mesmo grupo cultural partilham entre si de um número de experiências, de ensinamentos e de pontos de vista. No entanto, para além dessa estrutura comum, cada um dos indivíduos tende a ser altamente idiossincrático. As diferenças que existem na história da vida de cada um levam necessariamente a diferenças que existem nas informações memorizadas. Para além disso, tem sido demonstrado repetidamente que duas pessoas a testemunharem o mesmo acontecimento - até mesmo um acontecimento saliente e altamente memorável como é o de um acidente de viação - podem construir representações radicalmente diferentes desse acontecimento que se opõem entre si, não só no que se refere às interpretações feitas desse acontecimento, mas também no que se refere às memórias que têm dos factos físicos básicos (SPREBER; WILSON, 1986/2001, p. 46).

Portanto, a partir do pressuposto de que temos conhecimentos e representações diferentes, capacidades cognitivas diferentes, memórias diferentes, podemos afirmar que fazemos inferências diferentes sobre os mesmos fatos e eventos do mundo. Em efeito, mesmo que vivam na mesma casa e participem das mesmas atividades sociointeracionais, a capacidade cognitiva das pessoas é sempre uma atividade individual. Sperber e Wilson (1986/2001) complementam dizendo que:

Não construímos todos a mesma representação; por um lado, devido às diferenças dos nossos ambientes físicos mais reduzidos e, por outro, devido às nossas capacidades cognitivas. As capacidades perceptuais variam em eficácia de um indivíduo para outro. As capacidades inferenciais também variam, e não apenas na sua eficácia. As pessoas falam em línguas diferentes, acabaram por dominar conceitos diferentes; como resultado, podem construir representações diferentes e chegar a inferências diferentes. Têm também memórias diferentes. Por isso, nem que todos partilhassem o mesmo estreito ambiente físico, aquilo a que propomos chamar os seus 
ambientes cognitivos seria mesmo assim diferente (SPERBER; WILSON, 2001. p. 79).

Podemos afirmar também que nós, seres humanos, apenas "partilhamos" informações do ambiente físico, mas nunca do ambiente cognitivo. Portanto, é errônea a ideia de que "compartilhamos conhecimentos" e/ou "experiências" do mundo. Nossas representações de mundo serão sempre só nossas, de mais ninguém.

No caso da comunicação humana, como a intenção do interactuante é causar uma modificação no ambiente cognitivo do interagente, para que isso aconteça, ele (interactuante) deverá utilizar-se de procedimentos ostensivos ${ }^{6}$ que acredite serem relevantes para o interagente. Este, por sua vez, irá avaliar cognitivamente se o que ouve lhe é relevante e irá processar a informação nova por um princípio de custo benefício cognitivo: atingir um maior efeito cognitivo com um menor esforço no processamento.

A ostensão do interactuante tem por objetivo guiar a atenção do interagente para que este saiba que o que o interactuante está querendo informar lhe é realmente relevante. A ostensão consiste, basicamente, em dar pistas ao interagente sobre as intenções do interactuante, isto é, é uma forma de o interactuante demonstrar sua intenção comunicativa, de deixar explícito que tem algo relevante a dizer. A ostensão é, portanto, uma manifestação intencional. No entanto, cabe ao interagente aceitar esse estímulo ostensivo, podendo considerálo verdadeiro ou não. Pode-se afirmar então que, de acordo com a TR, a comunicação verbal baseia-se num modelo ostensivo-inferencial, em que a parte ostensiva é específica do interactuante e a inferencial, é do interagente.

O interactuante dará pistas de sua intenção informativa, enquanto o interagente fará inferências para compreender/interpretar o conteúdo da

\footnotetext{
${ }^{6}$ A ostensão é, segundo Sperber e Wilson (1986/2001, p. 93) "um comportamento que torna manifesta uma intenção de tornar alguma coisa manifesta" a alguém.
} 
elocução emitida pelo interactuante, se essa lhe for relevante. A ostensão é uma garantia tácita de relevância, pois ela guia o interagente às nossas intenções, de forma que ele acredite que o que vamos comunicar lhe será relevante. Para Sperber e Wilson (1986/2001), um comportamento ostensivo fornece evidências do pensamento de quem está envolvido no ato comunicativo. Nessa perspectiva, até o silêncio na comunicação pode vir a ser um ato ostensivo.

Temos assim, em nossa memória enciclopédica, um grande armazém e esquemas de suposições (formas lógicas) os quais no processo dedutivoinferencial vão se combinar com novos inputs. As entradas de dados e as suposições conceituais são processadas a partir de regras de dedução. Uma regra de dedução "é uma computação que se aplica às suposições em virtude de sua forma lógica, tanto a uma relação sintática de computação quanto a uma relação semântica" (SANTOS, 2009, p. 91). Uma das regras dedutivas mais relevantes para o processamento inferencial é a regra modus ponens “Se $\mathrm{P}$ então $\mathrm{Q}$ ”, a qual representamos na sequência.

$$
\begin{array}{ll}
\text { Entrada de dados (Input): } & \text { (a) } \mathrm{P} \\
& \text { (b) (Se P então Q) }
\end{array}
$$

Resultado (Output): Q

P e Q são premissas que contém as variáveis do processamento inferencial, onde $\mathrm{P}$ é a premissa que contém a informação nova a ser restringida às informações armazenadas na Memória Enciclopédica e Q é a variável conclusiva resultante dessa operação. Não se podem prever com antecedência quais e quantas serão as regras que o indivíduo utiliza no processamento cognitivo, mas como se verá adiante, é possível demonstrarmos descritivamente quais foram as possíveis inferências utilizadas pelos alunos brasileiros aprendizes de E/LE na produção (ou na interpretação) da escritura dos textos. 
De modo geral, as regras inferenciais estão intimamente ligadas à veracidade das premissas que incorporam a regra, tendo-se esta condição em relação a um estado de coisas no mundo. A meta cognitiva de relevância é uma aptidão individual, isto é, cada indivíduo seleciona cognitivamente as entradas de informações em nível de relevância dos enunciados. No entanto, essa meta só será conseguida se o indivíduo atingir um efeito contextual suficientemente capaz de provocar uma mudança em seu ambiente cognitivo. Entretanto, para que esse movimento mental seja completo, é necessária a junção de uma informação antiga à nova.

\section{DA METODOLOGIA E COLETA DE DADOS}

Usando os pressupostos pragmáticos da Teoria da Relevância (SPERBER; WILSON, 2001) a metodologia de trabalho é de análise qualitativa sobre os procedimentos inferenciais de produção textual de alunos brasileiros aprendizes de E/LE, do turno vespertino, da Universidade Estadual de Ponta Grossa, no ano de 2018. O grupo era formado por 18 alunos, sendo que a coleta de dados incidiu sobre 13 textos apenas, porque no dia da avaliação este era o número de alunos presentes. Por questões éticas, a identificação dos alunos foi preservada, uma vez que neste estudo interessa somente as produções textuais ${ }^{7}$. O grupo era bastante heterogêneo, sendo que muitos alunos já demonstravam o domínio sociodiscursivo na produção de textos orais e escritos em E/LE, com estruturas bem formadas, vocabulário nivelado com a série, formação de estruturas

\footnotetext{
${ }^{7}$ Por tratar-se de uma pesquisa que envolve as produções textuais, sendo essas produções colhidas com autorização dos alunos, seguimos a orientação do Professor Ulisses Coelho, Coordenador do Comitê de Ética em Pesquisa da UEPG, conforme conversa na data de 10 de outubro de 2018. Segundo o coordenador a resolução interna da UEPG, n 510, de 07 de abril de 2016, destaca em seu parágrafo único, inciso VII que "não serão registradas e nem avaliadas pelo sistema CEP/CONEP pesquisa que objetive o aprofundamento teórico de situações que emergem espontânea e contingencialmente na prática profissional, desde que não revelem dados que possam identificar o sujeito."
} 
sentenciais coerentes com o estágio em curso (conforme se pode verificar nos textos 1 e 2), enquanto outros ainda transitavam entre a influência de estruturas da LM e o domínio de padrões linguísticos de LE exigido para o nível da série em curso (vide textos 3 e 4 ).

A atividade proposta consistia em discorrer oralmente sobre a figura trazida pelo professor, na qual se configurava a cena de uma casa em total desordem. Como a figura estava em preto e branco, os alunos deveriam imaginar as cores dos objetos da figura. Na cena da figura podia ver-se cigarros, papéis escritos e dinheiro espalhados pelo chão do lado de fora da casa. Um pé de sapato estava ao lado dos papéis. A janela entreaberta apresentava o vidro quebrado. Pela porta entreaberta podia ver-se o interior da casa, onde aparecia uma cadeira caída. Na soleira da porta havia uma mancha escura, da qual os alunos sugeriram ser sangue. Na árvore ao lado da janela um pano sujo e pingando o mesmo material da soleira da porta. Na sequência apresentamos a figura descrita.

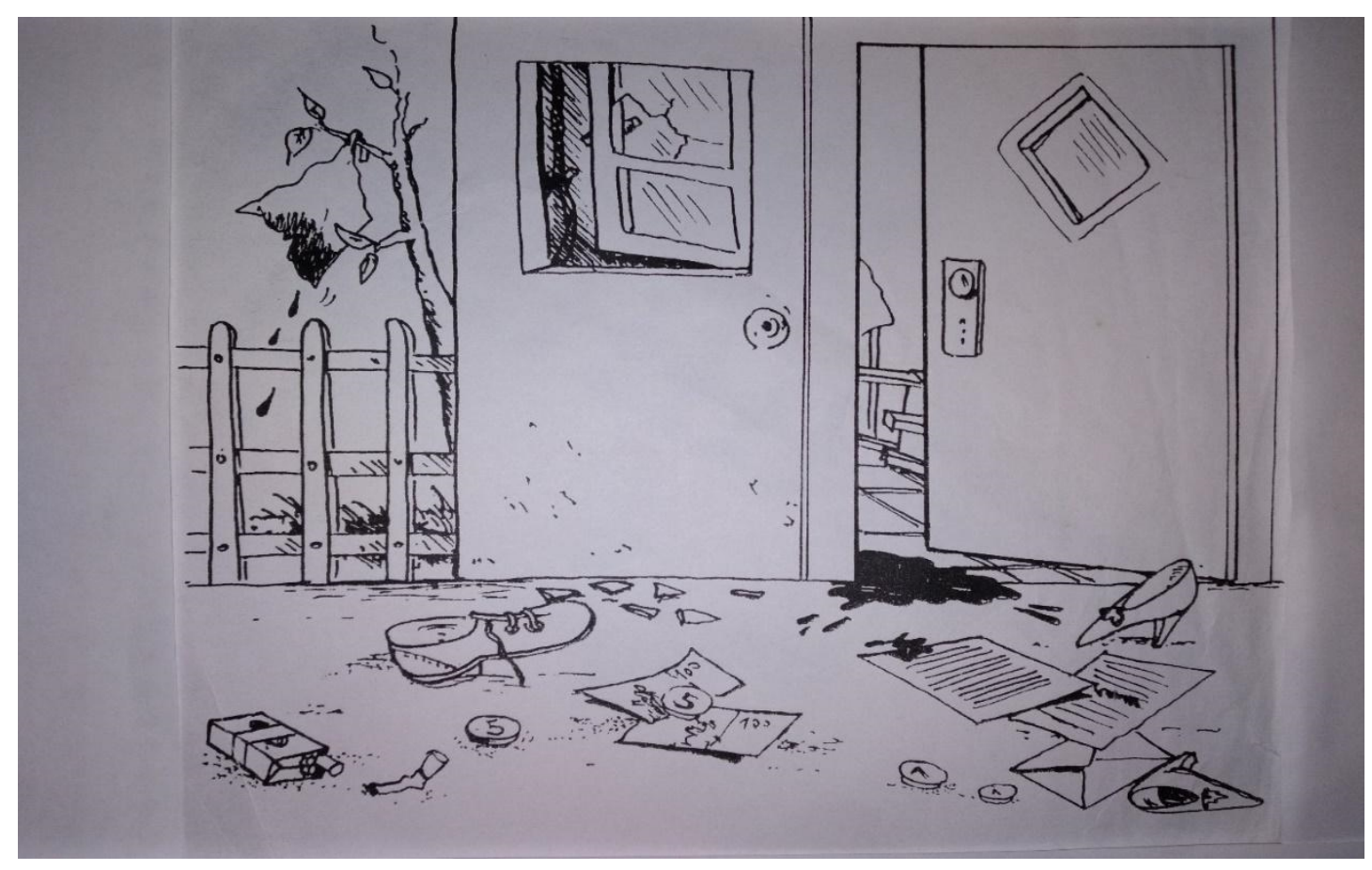

Fonte: Miquel e Sans, s/p, 1992. 
Como era uma aula de produção oral (conversação) em língua espanhola com a finalidade de produção escrita, a ideia era estimular as discussões orais para que cada aluno, ao expressar-se oralmente, pudesse dar sugestão sobre o que podia ter ocorrido ali. Por tratar-se de uma aula geminada, o tempo demarcado para as discussões foi de 20 minutos. Os objetivos da aula eram dois: a) por meio das discussões em grupo, estimular a produção oral individual e b) avaliar a competência comunicativa (CANALE, 1995), linguística e sociodiscursiva, na produção de textos. Ao final os alunos deveriam produzir um texto no qual expressassem suas percepções e representações sobre a cena da figura, a partir do que foi discutido oralmente.

Por falta de espaço, neste estudo analisamos 4 produções textuais, uma vez que a maioria dos textos apresentava-se linguisticamente coerente e consistente com os padrões normativos da linguagem escrita para a série em curso, conforme se pode observar nos textos 1 e 2 .

\section{Texto 1}

Era aproximadamente 22:00 horas de una noche de viernes, cuando yo y mis amigos (orden invertido) estábamos patrullando en nuestro barrio, cuando oímos gritos. Entonces yo y mis compañeros corrieron (concordancia) para ver lo que estaba pasando en la casa al lado, porque (pregunta indirecta) todo ese bullicio venido de allí. Llegando allí nos encontramos con las siguientes escenas: vidrio de la ventana rota, puerta abierta, utencilios (grafia) femeninos en el suelo de fuera de la casa y para nuestra sorpresa había una cuerda que parecía una horca y una almohada con sangre al lado de fuera de la casa colgado en la casa una rama de arbol vieja (acentuación).

\section{Texto 2}

Este caso es un homicidio. En la entrada de la puerta es posible ver un charco de sangre, el cuerpo de la víctima está recostado en la pared del lado de dentro de la casa, lo que explica la sangre esparcida por el suelo. La víctima es un hombre, muerto por su esposa que descubrió, a través de las cartas de la amante esparcidas por el suelo, la traición del marido. Se percibió (tiempo verbal) que hubo una pelea antes de ocurrir el asesinato, la silla de dentro de la casa está tirada en el suelo, varios elementos personales esparcidos en el exterior de la casa, el vidrio de la ventana roto después de ser arrojado un calzado hacia fuera. Debajo de la ventana, es posible percibir un agujero hecho con el tiro que 
mató al hombre, alcanzando un poco debajo del abdomen, atravesando su barriga y perforando la pared. Al lado de la casa, hay un pequeño árbol con un paño lleno de sangre colgada (concordancia) en una de las ramas, creo que la mujer, después de hacer el disparo contra su marido, se da cuenta de que fue demasiado lejos y entonces tomó el paño en el intento de interrumpir el sangrado, pero percibiendo que no tenía más que hacer, ella se desespera y huye, dejando atrás el paño colgado en el árbol.

Destacamos, contudo, que os textos 1 e 2 são tomados como amostras das 13 produções por apresentarem problemas pontuais que serão diluídos pelos alunos ao longo do curso, pois são problemas estruturais de interlíngua não fossilizáveis, isto é, fáceis de serem cognitivamente resolvidos. No entanto, 2 textos apresentam problemas estruturais bastante salientes, isto é, apresentam problemas mais relevantes de aprendizagem de E/LE por estudantes brasileiros, conforme podemos verificar nos textos 3 e 4 .

\section{Texto 3}

Yo creo que una pareja tebe una discusión, la mujer muy brava entró en la casa del novio y arrojó todas las cosas en el suelo. El marido intentó explicarse diciendo que nada sucedió y que estaba hablando la verdad. Pero ella no quiso oír y salió corriendo llorando. Y habló que el marido no tenía como negar que estaba con otra mujer pues vio ropas y vió zapatos en su cuarto, y habló le: ¡Explica los entonces! Como elle no sabía explicarse. Ella sé fue. Creo que no puede ser un robo porque el ladrón llevaría todo el dinero.

\section{Texto 4}

\section{El misterio de la casa abandonada}

En la imagen mostrada, me doy cuenta de que es la casa abandonada, donde se produjo una terrible tragedia. Con varios objetos jugados por lo suelo, vidrio de la ventana quebrado, sangre esparcida por todas las partes, la intuición que $(\varnothing)$ tuvo una gran pelea entra la mujer y un hombre, tal vez por exceso de celos, quien sabe causando así la muerte de una de las partes que estaba involucrado, pues la cantidad de sangre esparcida es mucho y es casi inevitable que $(\varnothing)$ haya sobrevivido. Pero no podemos descartar la oportunidad de que la persona $(\varnothing)$ esté viva, porque lo cuerpo no estaba en lo lugar, entonces no puedo considerar como asesinato sin que lo cuerpo aparezca. También percibí en la imagen que fue una pelea muy rápida, porque la puerta y la ventana de la casa están abiertas y con muchos objetos tirados fuera de la residencia, así 
percibiendo que si hubo un asesinato la persona $(\varnothing)$ salió a la prisa del lugar para esconder lo cuerpo.

\section{DA ANÁLISE PRAGMÁTICA}

Embora os textos 3 e 4 apresentem muitos problemas, quer de morfossintaxe, quer de coerência, quer de vocabulário, quer de regência ou de concordância, além de outros, nosso interesse neste estudo recai sobre dois problemas recorrentes a estudantes brasileiros aprendizes de E/LE. O primeiro caso - o uso do pronome sujeito "elle" (vide texto 3) - é bastante recorrente ao aluno brasileiro aprendiz de E/LE, porém não tanto quanto o segundo - o uso do artigo neutro "lo" em diversas situações (vide texto 4). Pelo viés da pragmática cognitiva da Teoria da Relevância (SPERBER; WILSON, 2001) nos próximos parágrafos descreveremos sucintamente como ocorre o movimento inferencial do processamento das informações pelos alunos na produção dos textos.

Seguindo os pressupostos da TR, para a produção textual escrita, durante a preleção da aula os alunos deveriam observar na figura: a) o que é (mais) relevante nessa cena? - Note-se que neste caso a ostensão é essencialmente visual. Essa indagação conduz a uma segunda: b) quais são os inputs visuais (mais) ostensivos? Pelos aportes teóricos da TR, para dar conta da produção textual os alunos deveriam criar mentalmente um ambiente cognitivo no qual pudessem representar a ocorrência da cena. Esse ambiente cognitivo, no ponto de vista da Pragmática Cognitiva, é um contexto. Pelas discussões entre pares e as ostensões do professor os alunos detinham material cognitivo suficiente para criar tal ambiente cognitivo que pudesse subsidiar a produção textual. Vale destacar que, embora os textos 3 e 4 apresentem problemas linguístico-discursivos mais gerais, por questões de espaço nos deteremos apenas nos problemas elencados no objetivo traçado para este artigo. 
No texto 3, na oração "Como elle no sabía explicarse. Ella sé fue" o aluno faz uso do pronome sujeito "elle" no lugar do pronome "él". Vale destacar também que embora o aluno tenha separado a oração em duas sentenças, mentalmente trata-se de uma única oração, uma vez que cognitivamente ambas as sentenças estão numa relação de contiguidade e complementaridade significativa.

São inúmeros os estudos de análise contrastiva que versam sobre este assunto - um dos mais conhecidos é o de Durão (2004). Lozado (2007), por exemplo, enumera diversos casos em que os aprendizes brasileiros de E/LE fazem uso do processo de transferência da LM sobre a LE. Casos como Cuando él quería ver el mundo, elle salía volando (LOZADO, 2007, p. 131) são recorrentes entre os brasileiros aprendizes de espanhol. Frigo (2006, p. 67), por sua vez, ressalta que esse caso é um fenômeno de transferência por hipercorreção, no qual o aprendiz brasileiro, por semelhança lexical, adapta a LM para a LE. Para Durão (2004), este é um processo de transferência lexical negativa. Segundo os autores, o processo de transferência negativa do pronome sujeito "él" não ocorre só sobre o construto "elle", mas também, e principalmente, sobre o demonstrativo neutro "ello". Por razões puramente técnicas, como destacado anteriormente, este estudo não versará sobre a forma "ello". Vale destacar, no entanto, que embora façam um excelente trabalho analítico contrastivo, nem Durão, nem Lozado nem Frigo explicam o processo inferencial de produção desse fenômeno linguístico.

Seguindo com nossos pressupostos cognitivistas, passamos a descrever na sequência o processamento inferencial sobre o fenômeno. Para dar conta da empreitada, partimos do princípio de que o conhecimento enciclopédico conhecimento relativo à Memória Enciclopédica (vide explicação nas páginas anteriores) - do aluno brasileiro aprendiz de E/LE detém alto grau de 
interferência da sua Língua Materna (LM), o Português Brasileiro (PB)8. Em efeito, na busca pela relação "maior efeito com menor esforço cognitivo" o aluno brasileiro recorre ao acervo mental da LM para produzir textos orais ou escritos na LE.

No percurso da aprendizagem dos pronomes sujeito da LE o aluno brasileiro de E/LE produtor do texto 3 processou, de acordo com a TR, informações que lhe foram relevantes, ou mais relevantes. Essas informações foram as que ficaram mais salientes na sua Memória Enciclopédica porque foram as que lhe proporcionaram maior efeito com um baixo custo de processamento. A pressuposição subjacente ao fenômeno é que, neste caso, o pronome "ella" é cognitivamente mais relevante que "él" ao aluno porque contém alto grau de novidade. Isto é, na aprendizagem foi o fato que mais lhe chamou a atenção porque a palavra contém duplo "1" (11). Ao revés, "él", embora devesse ter baixo custo de processamento cognitivo, foi-lhe menos relevante que "ella".

Deste modo, recorrendo à regra de dedução pragmática modus pones (Se $\mathrm{P}$ então Q) proposta pela TR, o processo inferencial de produção escrita do aluno no texto 3 se processou como segue:

SE o pronome "ela" da LP equivale a "ella" na LE (premissa P), ENTÃO o pronome "ele" da LP corresponde a "elle".

Conclusão Q: “ele” da LP corresponde a “elle” em LE.

Note-se que, segundo a TR, este é um tipo de raciocínio lógico sobre a inferência não demonstrativa, em que a conclusão sobre as premissas de entrada não pode ser cognitivamente comprovada, apenas confirmada. De acordo com

\footnotetext{
${ }^{8}$ De acordo com Silva (2015), a interferência é adoção de formas ou estruturas da língua materna (LM) ou de outras línguas segundas (L2) ou estrangeiras (LE) que o estudante conhece. Segundo a autora, "a interferência é um processo que acontece quando há convergência de duas ou mais línguas cujas regras não se correspondem" (p. 14).
} 
Frigo (2006) este fenômeno retrata um caso de transferência lexical por semelhança - o fenômeno corresponde a um processo de transferência lexical negativa por hipercorreção. Vale destacar que, cognitivamente, este processo inferencial engloba dois níveis cognitivos de falseamento: falsa seleção e falsa analogia (conceitos descritos em Durão, 2004, e Eckert, 2014). Aqui é interessante distinguir ambos os conceitos.

Discordamos dos autores que adotam os conceitos como sinônimos, posto que a falsa analogia é uma atividade inferencial inerente à cognição humana, isto é, é uma ação mental natural atrelada aos desejos e intenções dos indivíduos. Como inferência, a falsa analogia é um processo mental de interpretação e representação das coisas do mundo. Por sua vez, a falsa seleção é um fenômeno cognitivo derivado do primeiro e se caracteriza por trabalhar com o conhecimento enciclopédico, isto é, a falsa seleção é o fenômeno cognitivo atrelado à manipulação daquilo foi aprendido e apreendido do mundo pelo indivíduo. A falsa seleção municiona a falsa analogia com material cognitivo da Memória Enciclopédica para as inferências. Em efeito, se a falsa seleção seleciona "produtos" falsos, a operação feita pela cognição será igualmente falseada, o que resulta em falsa conclusão. Resumidamente a falsa analogia é um processo a priori e a falsa seleção um processo a posteriori.

Especulando um pouco mais nós diríamos até que a falsa analogia não é "falsa", posto que a "analogia" é um processo naturalmente dinâmico de processamento mental. Então, a “analogia" é parte do sistema inferencial humano que independe da verdade das premissas. Aceitar isso requer a presunção de um filtro cognitivo de validação da verdade das premissas processadas. Esse filtro é, cognitivamente, feito pela "falsa seleção", que opera e valida somente inputs verdadeiros.

Na sequência, passamos a discorrer sobre o texto 4 . O uso do pronome neutro "lo" no lugar do artigo definido masculino singular "el" por estudantes 
brasileiros aprendizes de espanhol é um fenômeno linguístico recorrente nas séries iniciais dos cursos de E/LE. Espera-se, no entanto, que no segundo ano o aluno brasileiro já tenha uma competência sociopragmática capaz de conseguir desvencilhar-se das amarras do processo de interlíngua na transferência da LM sobre a LE. Contudo, não é isso que se verifica no texto 4 . Neste texto inferimos que o aluno detém o conhecimento linguístico sobre o uso do artigo definido masculino singular em LE, uma vez que, pelas evidências do título, usa corretamente o artigo definido "el".

$\mathrm{Na}$ linha contrastivista são muitos os estudos que abordam os erros cometidos por brasileiros aprendizes de espanhol. Eckert (2014) ao fazer uma varredura na Biblioteca Digital de Teses e Dissertações da CAPES localizou em torno de duas dezenas de teses e/ou dissertações sobre a Interlíngua de brasileiros aprendizes de ELE, todas amparadas nos pressupostos teóricometodológicos da Linguística Contrastiva (Análise Contrastiva, Análise de Erros e Interlíngua). Autores como Durão (2004), Frigo (2006), Lozado (2007), Andrade (2011), Fernandes (2011), Carvalho (2013), Eckert (2014), Moysés (2014) e Silva (2015), entre outros, em seus estudos, fazem uma recompilação dos principais erros do aluno brasileiro aprendiz de espanhol. São abundantes os exemplos que esses estudiosos elencam, sendo os casos dos mais variados.

Um exemplo bastante conhecido dos professores de espanhol é tratado por Durão (2004): Lo hombre era flaco. Eckert (2014, p. 109) afirma que nesse exemplo, “o erro se dá por falsa analogia, uma vez que o aluno faz a relação entre os artigos femininos 'la - las' e consequentemente 'lo - los', e os compara ao português 'a - as', 'o - os'”. Durão (2005) relata que o problema não está na utilização do neutro em si, mas no fato do aluno inferir, a partir da LM, que o singular de "los" é "lo" e não "el". Vale notar que Durão reconhece a inferência como sendo o processo responsável pela dedução do aluno. No entanto, nem 
Eckert nem Durão dão maiores explicações sobre o tipo de relação e o tipo de inferência que o aluno realiza no processo.

Gramaticalmente", de acordo com Torrego (2000), o artigo neutro "lo" nunca vai diante de um substantivo, uma vez que não existem substantivos neutros em espanhol, nem designa gênero ou número. Por conseguinte, se usa "lo" diante de adjetivos, advérbios, particípios, de preposições, pronomes possessivos e relativos. Nestes contextos, "lo" cumpre diferentes funções, como a de substantivar e intensificar o valor dos adjetivos, dos advérbios e particípios, além de fazer referência a situações passadas ou coisas conhecidas pelo interagente.

Em linhas gerais, as gramáticas tradicionais espanholas classificam o uso de "lo" em três categorias - referencial, enfático e demais casos - sendo que estas categorias se subdividivem em outras subcategorias.

1) "Lo" referencial: $\mathrm{O}$ "lo" referencial, como o nome diz, faz referência a elementos abstratos ou inanimados e se usa diante de adjetivo, particípio, advérbio, e em estruturas como "lo + que" ou "lo + de". Exemplos:

1) Lo + adjetivo: Mira, lo guapa que está María.

2) Lo + particípio: Lo prohibido le encanta.

3) Lo + advérbio: Lo (más) triste es saber que te perdí.

4) Lo + que: Lo que quiero decir es que él me da calofríos. Lo + de: Quedamos en lo de Juan

2. Lo enfático: $\mathrm{O}$ "lo" enfático intensifica o valor dos adjetivos, dos advérbios e dos particípios. Sempre vai antes do relativo que: Exemplos:

1) Lo + adjetivo + que: Tú no sabes lo inteligente que es esta mujer

2) Lo + adverbio + que: Tú no sabes lo lejos que vivo.

3) Lo + participio + que: !Mira lo rota que está la bici!

\section{Outros usos:}

a) Para fazer referencia a situações passadas ou coisas conhecidas pelos interagentes. Exemplo: Juan llegó retrasado en lo de Carmen.

b) Com pronomes possessivos: Exemplo: Lo tuyo es mejor que lo mío.

\footnotetext{
${ }^{9}$ Diferentemente da nota 2, mas na mesma linha de Possenti (1996), o conceito de "gramática" neste tópico tem a acepção linguística tradicional de normativa ou padrão.
} 
Sobre o erro do aluno no texto 4, Durão e Schardosim (2011) explicam que do ponto de vista linguístico, o erro pode ser de falsa seleção; do ponto de vista gramatical, o erro pode ser ortográfico e morfológico; do ponto de vista etiológico, além de ser intralinguístico, o erro pode ser também transitório ou permanente (fossilizado ou fossilizável). Já do ponto de vista pedagógico, o erro pode ser de compreensão, produção, coletivo, oral e escrito.

De acordo com Carvalho,

[...] a palavra erro remete-nos para vocábulos como incorreção, desvio, inadequação, transgressão ou afastamento em relação às normas ou regras estabelecidas. $\mathrm{O}$ erro ocorre quando o aluno não encontra nos seus conhecimentos da LE a resposta que necessita para estabelecer a comunicação, recorrendo a elementos que crê poderem colmatar essa falha ou incapacidade (2013, p. 21-22).

Mais:

[...] o erro pode ser encarado de duas formas completamente opostas: por um lado, significa a prova do fracasso dos alunos na aprendizagem e da incapacidade do professor em levá-los a aprender, devendo ser a todo o custo evitado; por outro lado, simboliza uma etapa essencial já que, ao cometê-lo, o aluno está a aprender e a progredir, sendo um mecanismo necessário, natural e tolerado no processo de aquisição da LE e uma importante fonte de informação acerca do estádio de aprendizagem em que o estudante se encontra (CARVALHO, 2013. p. 22).

Silva (2015), ao abordar os tipos de erros cometidos por aprendizes lusofalantes se alinha a Durão (2007) e defende a segunda linha de Carvalho. Para a pesquisadora o estágio de aprendizagem em que se encontram os alunos produtores dos textos 3 e 4 corresponde à "Interlíngua". De acordo com Silva,

A interlíngua constitui uma etapa obrigatória na aprendizagem e define-se como um sistema linguístico interiorizado que evolui e que se vai tornando cada vez mais complexo, e sobre o qual o aluno possui intuições. Este sistema é diferente do da língua materna e do da língua meta, mas também não é 
uma mistura dos dois [...]. De todas as características da interlíngua, uma das mais relevantes é o mecanismo da fossilização, um fenómeno pelo qual o falante não nativo tende a conservar na sua interlíngua formas, regras e subsistemas errados, de maneira recorrente e em estados da aprendizagem em que estes esquemas já deveriam estar superados. [...]

Assim, podemos dizer que a interlíngua é uma linguagem específica do aluno porque ainda não é a língua que está a aprender, mas também já não é a sua língua materna. Aqui os erros já não são encarados como algo negativo, mas sim como uma fase ativa do aluno perante a aprendizagem da língua estrangeira. (SILVA, 2015, p. 7).

Frigo (2006) destaca que as interferências da LP na aprendizagem de E/LE por brasileiros são muitas, porque o aluno brasileiro estabelece um grande número de pontos coincidentes com a LP brasileira. De acordo com o autor, o aluno brasileiro aprendiz de espanhol acredita que recorrendo à LM vai encontrar a solução para suas falhas na aprendizagem de LE. Contudo, em vez de se exprimir em LE acaba por se comunicar numa espécie de mistura entre as duas línguas. É o que se conhece como portunhol ${ }^{10}$.

Para Eckert (2014) o erro no texto 4 não pode ser descrito como fossilizado porque cognitivamente é um caso típico de estratégia de generalização do aluno brasileiro. De acordo com o pesquisador, o aluno aplica o mesmo processo de “espanholização" do artigo feminino ao masculino, isto, é: como o artigo "a" feminino corresponde ao artigo "la" feminino, o artigo "o" corresponde ao artigo "lo". O autor não faz nenhuma menção, mas acreditamos que o raciocínio do aluno é do tipo de inferência que descrevemos anteriormente, ou seja, a inferência modus ponens.

Quando Durão (2004) e Eckert (2014, p. 109) afirmam que o aprendiz brasileiro de Língua Espanhola faz a relação, ou inferência, entre os artigos femininos 'la - las' e consequentemente 'lo - los', e os compara aos artigos do

\footnotetext{
${ }^{10}$ De acordo com Frigo (2006, p. 1) “A interlíngua do aprendiz brasileiro aprendendo espanhol como LE é reconhecida informalmente como "portunhol" e se refere à criação de um sistema lexical particular em que são combinados lemas e lexemas das duas línguas".
} 
português 'a - as', 'o - os', os autores explicaram apenas a metade da coisa. A outra metade será explicada na sequência, pela ótica da Pragmática Cognitiva da Teoria da Relevância (TR). A regra inferencial usada pelo aluno, como descrito anteriormente, é a regra inferencial modus ponens. Aplicando esta regra (Se P então Q) à análise do texto, o raciocínio de “espanholização" (ECKERT, 2014) elaborado pela cognição do aluno ocorre da seguinte maneira:

SE o artigo "a" da LP corresponde ao artigo "la" da LE (premissa P), ENTÃO o artigo "o" da LP corresponde ao artigo "lo" (conclusão Q).

De acordo com Sperber e Wilson (1986/2001) este é um processo em que o raciocínio inferencial obtém maior relevância, porque é o raciocínio que guia a cognição do aluno na busca de maior efeito com menor esforço.

Um caso igualmente emblemático da Língua Espanhola para o aprendiz brasileiro é descrito por Eckert (2014) em que há vacilação do aprendiz quanto ao uso do artigo definido ou do neutro. Nas orações “El vino es el mejor que he probado" e "El vino es lo mejor que he probado", de acordo com o autor, se o aluno não realizar "as inferências adequadas, não conseguirá compreender a diferença de sentido ao ler as duas construções" (p. 110).

Note-se que a descrição e a explicação do caso não é da competência das relações morfossintáticas comumente descritas nas regras das gramáticas tradicionais. Não é nem um caso de falsa seleção nem de falsa analogia, porque o uso de uma ou outra forma vai implicar no significado que o interactuante tem a intenção de informar. É, portanto, um caso de descrição e análise pragmática. Quando o interactuante usa a oração 1 "El vino es el mejor que he probado" ele implica (significa) que "esse vinho é o melhor vinho que ele já provou". Por outro lado, ao usar a oração 2 "El vino es lo mejor que he probado", o interactuante generaliza um conceito e implica (significa) que "esse vinho é a melhor coisa que ele provou". 


\section{CONSIDERAÇÕES FINAIS}

A partir das explicações e descrições feitas nos parágrafos anteriores concluímos que o uso competente dos pronomes "él" e do artigo neutro "lo" em Língua Espanhola por estudantes brasileiros ainda é um objetivo a ser atingido, posto que dos 13 textos analisados, muitos deles ainda conservam traços da interferência do PB na aprendizagem de E/LE. Por exemplo: vimos que nos contextos em que os aprendizes deveriam usar o pronome "él" usam o construto "elle", bem como o artigo definido "el", por uma inferência de falsa analogia provocada por falsa seleção, é substituído pelo artigo neutro "lo". Neste caso, o equívoco ocorre porque na LM do estudante brasileiro há uma única forma para o artigo definido masculino singular, enquanto que na Língua Espanhola há uma forma para o artigo definido masculino e outra para o artigo neutro.

Também há equívoco do estudante brasileiro aprendiz de E/LE quando quer destacar o significado implicado nas elocuções, pois há vacilação em estruturas morfossintáticas, sintáticas, semânticas e pragmáticas. No texto 1, por exemplo, há inversão na ordem sintática de colocação dos elementos. Na primeira sentença, no fragmento "cuando yo y mis amigos estábamos patrullando en nuestro barrio" a ordem sequencial em Língua Espanhola é "cuando mis amigos y yo estábamos patrullando en nuestro barrio". O fragmento “Entonces yo y mis compañeros corrieron para ver lo que estaba pasando en la casa al lado, porque todo ese bullicio venido de allí" apresenta dois problemas estruturais: $1^{\circ}$ ) o verbo "correr" para "nosotros" está flexionado incorretamente: nosotros corrimos. $2^{\circ}$ ) o "porque" leva acento, pois faz referência a uma pergunta indireta: "Entonces mis compañeros y yo corrimos para ver lo que estaba pasando en la casa al lado, porqué todo ese bullicio venido de allí." Por sua vez

o fragmento "Llegando allí nos encontramos con las siguientes escenas: vidrio de 
la ventana rota, puerta abierta, utencilios femeninos en el suelo de fuera de la casa y para nuestra sorpresa había una cuerda que parecía una horca y una almohada con sangre al lado de fuera de la casa colgado en la casa una rama de arbol vieja" apresenta também dois problemas estruturais. O primeiro é de grafia (a palavra utensílios se grafa com "s") e o segundo é de acentuação (árbol).

No texto 2, no fragmento "Se percibió que hubo una pelea antes de ocurrir el asesinato, la silla de dentro de la casa está tirada en el suelo,..." o problema é de tempo verbal. Como se trata de uma narrativa em que há alternância dos tempos verbais conforme o texto vai seguindo linearmente, neste ponto o tempo verbal correto é presente do indicativo"1. Portanto: "Se percibe que hubo una pelea antes de ocurrir el asesinato, la silla de dentro de la casa está tirada en el suelo,...". Já no fragmento "Al lado de la casa, hay un pequeño árbol con un paño lleno de sangre colgada en una de las ramas," o problema é de concordancia: "paño" é masculino e o adjetivo foi equivocadamente usado no feminino.

Quando escrevemos anteriormente que das 13 produções, a maioria dos textos apresentava-se linguisticamente coerente e consistente com os padrões normativos da linguagem escrita, é a isto que nos referíamos. Os textos apresentam problemas estruturais pontuais que serão, seguramente, resolvidos pelos alunos ao longo do curso, uma vez que a aquisição da competência comunicativa tende a ser linguisticamente eficaz.

Os casos analisados nos textos 3 e 4, embora tratados pelos estudos da linguística contrastiva, não são devidamente explicados, são apenas descritos contrastivamente. Como vimos, a explicação de como se processa o movimento inferencial de aprendizagem das especificidades da LE por falantes brasileiros é da competência da Pragmática Cognitiva. Nessa acepção, a regra inferencial

\footnotetext{
${ }^{11}$ De acordo com Bosque (1990), aspectualmente o pretérito indefinido remete a um evento acabado, finalizado ('Se percibió' uma única vez). O presente do indicativo remete à ideia de temporalidade momentânea à elocução.
} 
modus ponens "Se P então Q" é o principal recurso cognitivo (mas não o único) utilizado pelo aprendiz brasileiro na análise, interpretação e produção de estruturas linguísticas da Língua Espanhola, o que faz do seu uso uma recorrência bastante frequente. Aceitar essa ideia equivale a responder a indagação que fizemos nas páginas iniciais.

E por fim ressaltamos, contudo, que este estudo não esgota o tema, mas pode jogar um pouco de luz sobre os processos inferenciais humanos na aprendizagem de línguas estrangeiras.

\section{REFERÊNCIAS}

ANDRADE, Otávio Goes de. Interlíngua oral e léxico de brasileiros aprendizes de espanhol. Londrina: Eduel, 2011.

ABADIA, Pilar Melero. Métodos y enfoques en la enseñanzalaprendizaje del español como lengua extranjera. Madrid: Edelsa, 2000.

BAR-HILLEL, Yehoshua. Expressões indiciais. In Marcelo Dascal (Org.). Fundamentos metodológicos da linguística - pragmática: problemas, críticas, perspectives da linguísticabibliografia. Vol. IV. Pragmática. Campinas: Unicamp, 1982, p. 23-49.

BOSQUE, Ignacio. Tiempo y aspecto en español. Madrid: Cátedra, 1990.

CANALE, Michael. De la competencia comunicativa a la pedagogía comunicativa de lenguaje. In LLOBERA, Michael. et al. Competencia comunicativa: documento básico en la enseñanza de lenguas extranjeras. Madrid: Edelsa, 1995.

CARVALHO, Helena Maria Daniel de Melo. Erros produzidos pelos alunos de espanhol/língua estrangeira por influência do português/língua materna. 2013. 149 f. Relatório de Estágio. Faculdade de Letras. Universidade de Coimbra, Coimbra.

DURÃO, Adja Balbino de Amorim Barbieri. Análisis de errores en la interlengua de brasileños aprendices de Español y de Españoles aprendices de Portugués. Londrina: Edeuel, 2004.

DURÃO, Adja Balbino de Amorim Barbieri. La interferencia como causa de errores de brasileños aprendices de español. In: SEDYCIAS, João. (org.). O ensino do espanhol no Brasil: passado, presente, futuro. São Paulo: Parábola, 2005.

DURÃO, Adja Balbino de Amorim Barbieri. La interlengua. Madrid: Arco Libros, 2007.

DURÃO, Adja Balbino de Amorim Barbieri; SCHARDOSIM, Chris Reyes. Análise de erros na interlíngua escrita observada em uma sala de aula de espanhol como língua estrangeira. In XIII Simpósio nacional de Letras e Linguística e III Simpósio Internacional 
de Letras e Linguística, 2011. Uberlândia: SILEL, novembro de 2011, Volume 2, Número 2. EDUFU, 2011. Disponível em http://www.ileel.ufu.br/anaisdosilel/pt/edicao_volume_2_numero_2.php. Acesso em 10/11/2020.

ECKERT, Kleber. O uso do artigo neutro 'lo' por aprendizes de espanhol como língua estrangeira: uma questão de língua e leitura. 2014. 160 f. Tese. Doutorado em Letras. Universidade de Caxias do Sul/UniRitter, Caxias do Sul.

FRIGO, Kelly Cristina. Os semelhantes se atraem? um estudo sobre a aprendizagem da língua espanhola por falantes brasileiros. 2006. 111 f. Dissertação. Mestrado em Letras. Setor de Ciências Humanas, Letras e Artes. Universidade Federal do Paraná, Curitiba.

LOZADO, Patrícia Rosa. A aquisição dos pronomes pessoais da língua espanhola por falantes de português do Brasil: aspectos lingüísticos e psicotipológicos. 2007. 182 f. Dissertação. Mestrado em Análise do Discurso. Instituto de Letras. Universidade de Brasília, Brasília.

MERCIER, Hugo; SPERBER, Dan. The enigma of reason: a new theory of human understanding. Cambridge, Massachusetts: Harvard University Press, 2017.

MIQUEL, Lourdes; SANS, Neus. De dos en dos: actividades interactivas de producción oral. Madrid: Difusión S. L. 1992.

PÉREZ, Aquilino Sánchez. Hacia un método integral en la enseñanza de idiomas. Madrid: SGEL, 1999.

POSSENTI, Sírio. Por que (não) ensinar gramática na escola. São Paulo: Mercado de Letras, 1996.

SANTOS, Sebastião Lourenço dos. A interpretação da piada na perspectiva da teoria da relevância. 2009. 329 f. Tese. Doutorado em Letras. Setor de Ciências Humanas, Letras e Artes. Universidade Federal do Paraná, Curitiba.

SANTOS, Sebastião Lourenço dos. Contexto e contextualização: quando o significado acontece. In VII Círculo de Estudos em Linguagem, 2013. FACHLA-UEPG. Linguagem, identidade e subjetividade no breve século XX. Ponta Grossa: CIEL, p. 700-709, junho de 2013. Disponível em http://sites.uepg.br/ciel/. Acesso em 10/11/2020.

SILVA, Daniela Martins dos Santos. Análise de erros na expressão escrita na aprendizagem do Espanhol. 55 f. 2015. Dissertação. Mestrado em Estudos didáticos, culturais, linguísticos e literários. Faculdade de Letras. Universidade de Beira Interior, Beira.

SPERBER, Dan; WILSON, Deidre. Relevância: comunicação e cognição. Lisboa: Fundação Calouste Gulbenkian, 2001.

TORREGO, Leonardo Gómez. Gramática didáctica del español. $7^{\mathrm{a}}$ ed. Madrid: Ediciones SM, 2000.

Nota do editor:

Artigo submetido para avaliação em: 16 de setembro de 2020.

Aprovado em sistema duplo cego em: 18 de novembro de 2020. 